\title{
Silicone tube stenting in endonasal dacryocystorhinostomy
}

\author{
Marco Carifi • Bruno Zuberbuhler • \\ Gianluca Carifi
}

Received: 25 March 2012/Accepted: 13 June 2012/Published online: 24 June 2012

(C) Springer-Verlag 2012

\section{Dear Editor,}

We read with interest the recent article from Dr Saeed [1].

The author achieved a remarkable $100 \%$ of success rate following endoscopic dacryocystorhinostomy (EN-DCR) without employing silicone tube stenting. However, he did not report whether they were all primary cases. In fact, whereas avoiding stenting is in line with more recent evidence [2,3], silicone tubes are often employed in revision DCR [4].

The intended purpose of the article was to propose guidelines as to when employ or not the adjuvant procedure.

In particular, the author suggested considering tube stenting for patients with stenosed lacrimal puncti ("second of the clinical criteria"). In this respect, it has to be highlighted that silicone tubes would not have effect on it, and other procedures such as punctoplasty are to be employed. A nasolacrimal duct obstruction gives indication for DCR, which creates a direct bypass between the lacrimal sac and the nasal cavity, whereas conjunctivorhinostomy must be considered in case of more proximal obstructions [5].

When assessing the effect of any additional procedure or adjuvant on the surgical success rate in EN-DCR, the osteotomy size represents a fundamental factor as it can influence the success rate $[4,6]$. Therefore, we would stimulate $\mathrm{Dr}$ Saeed to provide some information in that respect.

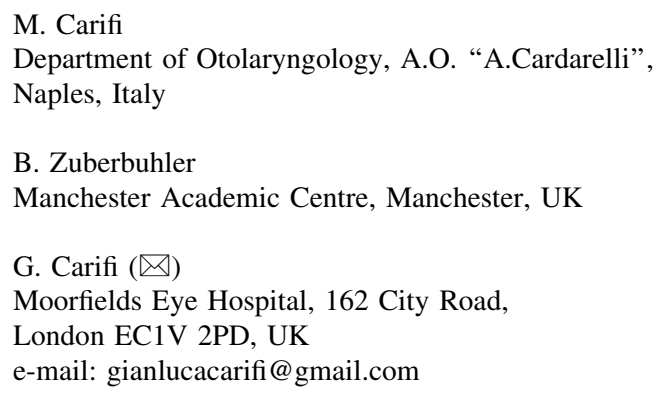

Finally, we would challenge him to agree that proper clinical investigation should be always performed to ascertain the existence of complete lacrimal drainage system and locate the site of obstruction. Probing the lacrimal canaliculi and, particularly, syringing is essential. Easily, a low obstruction is manifested by the fluid regurgitating through the upper punctum and the absence of fluid passed into the nasopharynx.

Whereas it is acceptable avoiding instrumental investigations, which could better confirm the diagnosis and exclude the presence of neoplastic etiology, we query why the author considered the simple clinical assessment not required.

Conflict of interest Authors do not have financial interest or conflict of interest to disclose.

\section{References}

1. Saeed BM (2012) Endoscopic DCR without stents: clinical guidelines and procedure. Eur Arch Otorhinolaryngol 269: 545-549

2. Leong SC, Macewen CJ, White PS (2010) A systematic review of outcomes after dacryocystorhinostomy in adults. Am J Rhinol Allergy 24:81-90

3. Smirnov G, Tuomilehto H, Teräsvirta M, Nuutinen J, Seppä J (2008) Silicone tubing is not necessary after primary endoscopic dacryocystorhinostomy: a prospective randomized study. Am J Rhinol 22:214-217

4. Kominek P, Cervenka S, Pniak T, Zelenik K, Tomaskova H, Matousek P (2011) Revision endonasal dacryocystorhinostomies: analysis of 44 procedures. Rhinology 49:375-380

5. Duffy MT (2000) Advances in lacrimal surgery. Curr Opin Ophthalmol 11:352-356

6. Konuk O, Kurtulmusoglu M, Knatova Z, Unal M (2010) Unsuccessful lacrimal surgery: causative factors and results of surgical management in a tertiary referral center. Ophthalmologica 224:361-366 